\title{
THE IMPACT OF HORMONAL PROFILE ON ANTIDEPRESSANT-INDUCED WEIGHT GAIN IN PATIENTS WITH DEPRESSION
}

Rukavishnikov G.V. ${ }^{1}$, Neznanov N.G. ${ }^{1}$, Mazo G.E. ${ }^{1}$, Kibitov A.O. ${ }^{1,2}$ -1 - V.M. Bekhterev National Medical Research Center for Psychiatry and Neurology, St.-Petersburg, Russia -2 - Serbsky National Medical Research Center on Psychiatry and Addictions, Moscow, Russia

\section{BACKGROUND AND AIMS}

The aim of our study was to analyze the impact of hormonal profile on metabolic syndrome and antidepressant-induced weight gain in patients with major depressive disorder.

\section{MATERIALS AND METHODS}

89 inpatients with major depression (74\% females, mean age $-45,04 \pm 11,4$ years) were evaluated at baseline and after 6 weeks of antidepressant therapy (SSRI, TCA). Clinical evaluation (weight, $\mathrm{BMI}$, waist circumference; waist-hip ratio: weight gain), psychometric instruments (HDRS-17, DEBQ) and laboratory panel (thyroid hormones, sex steroids, leptin, insulin, lipidogram) were used in the assessment.

\section{RESULTS}

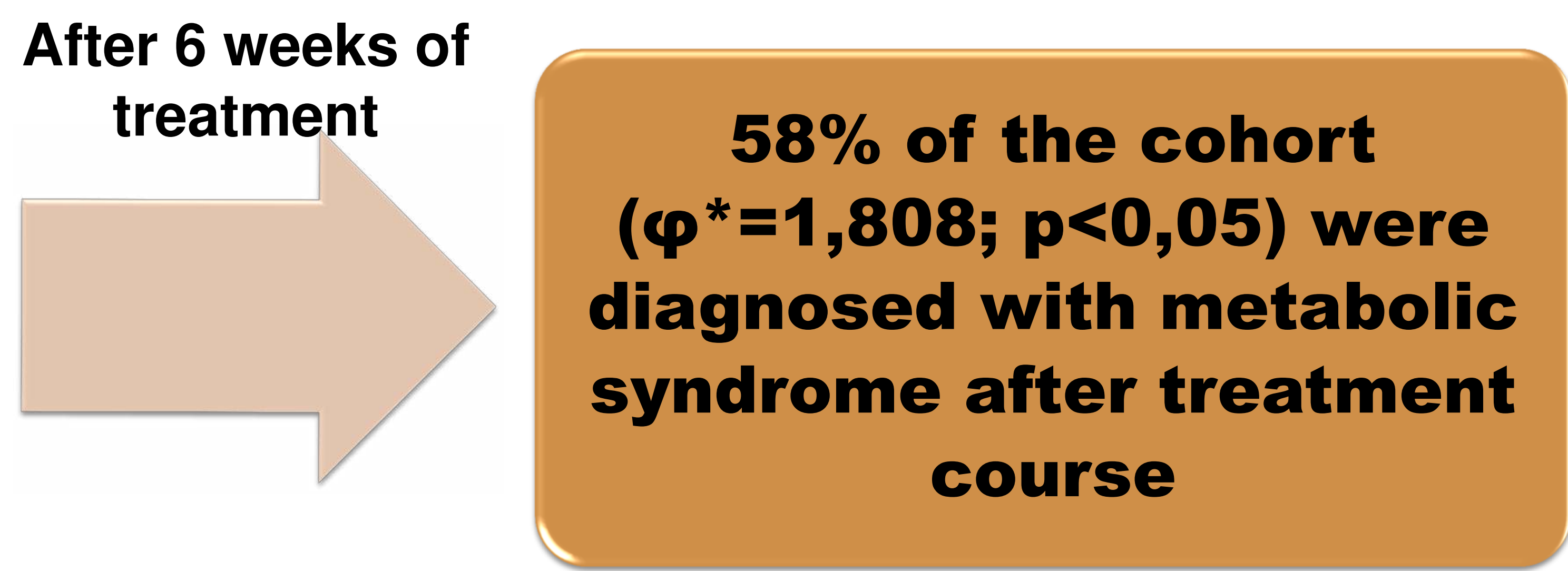

$45 \%$ of the patients were diagnosed with metabolic syndrome during initial evaluation course

Hormonal profiles of higher risks of antidepressant-induced weight gain at baseline

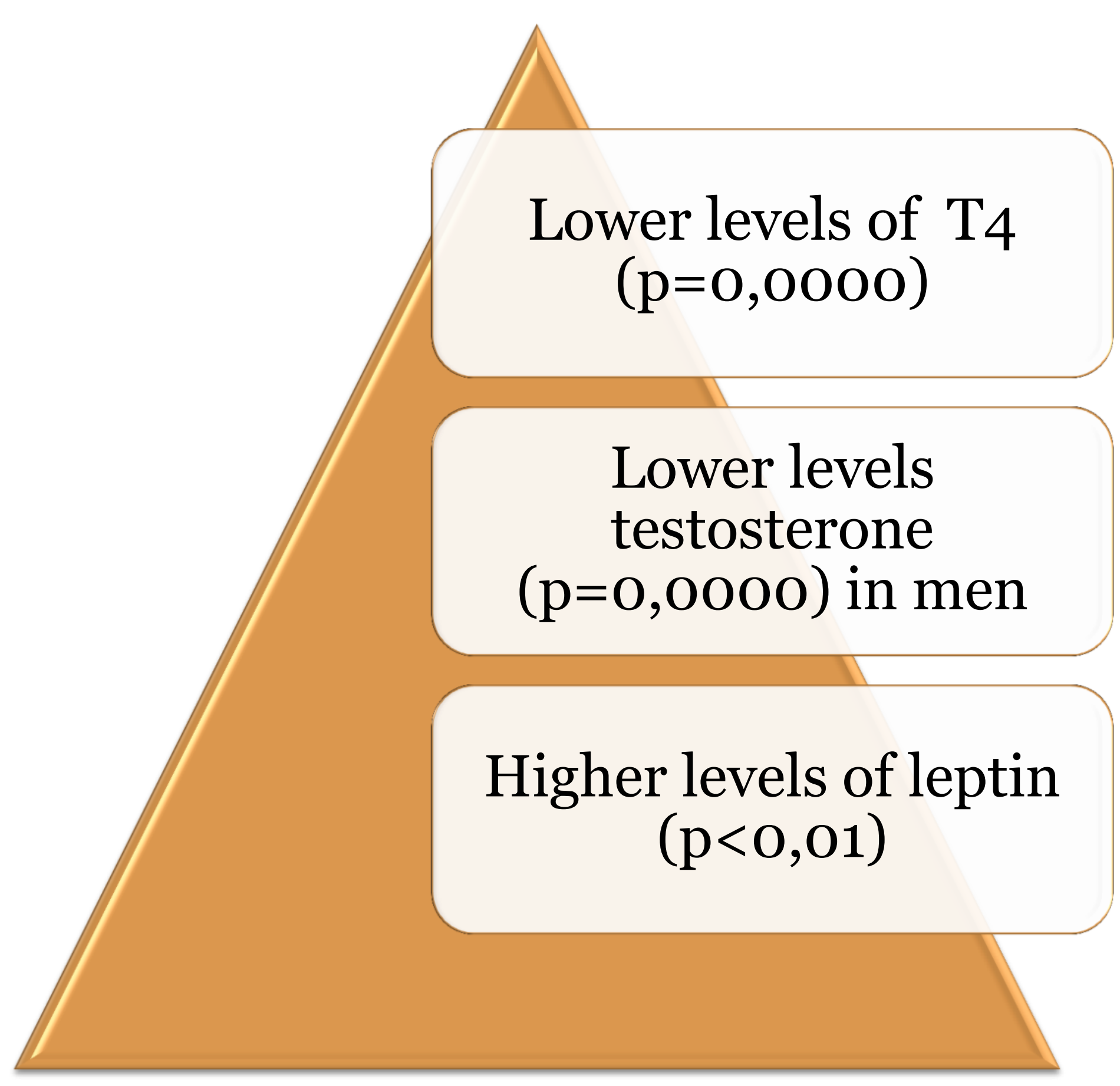

Hormonal profiles of higher risks of antidepressant-induced weight gain during treatment process

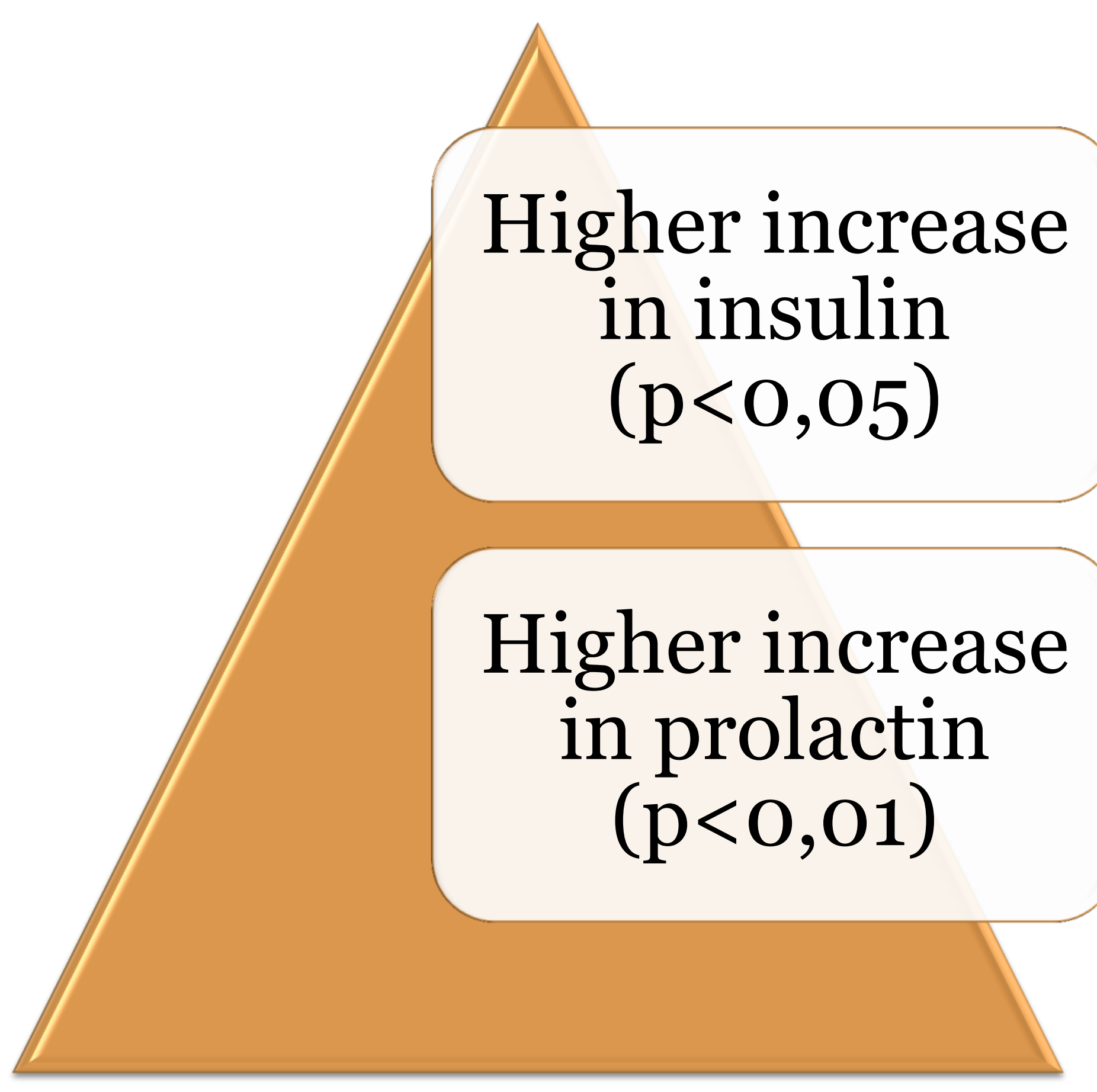

\section{CONCLUSIONS}

Certain hormonal profiles are associated with the higher risks of antidepressant-induced weight gain and could be used as the predictors of metabolic side-effects in patients receiving antidepressant treatment. 